\title{
水利工程对生态环境的影响及生态水利工程研究
}

\author{
王啸林 李献峰 王一宁 \\ 德州水利局
}

DOI:10.32629/hwr.v4i5.2949

[摘 要] 经济社会的快速发展对于资源的需求不断增大, 近几年, 水利工程建设发展很快。人们对城市的品味也随着提出了更高的要求, 很多经 济发达的地区提出了建设 “生态城市” 的发展目标。水利工程建设是我国重要的民生工程,其大大增加人们生活的便利性,为人类社会创造更高 的经济效益。基于此, 本文主要以生态水利工程的建设原则为切入点,分析水利工程对生态环境的影响, 以及阐述建设生态水利工程的几点建议, 仅供参考。

[关键词] 水利工程; 生态环境; 影响; 生态水利

\section{1 生态水利工程建设的原则}

1. 1 恢复和保护多样化河流的原则。不同的河流, 其土壤状况、流水状 态均各不相同, 这实际上就充分体现了河流的多样性, 因此, 在开展生态水 利工程建设的过程中, 应该充分考虑到项目的的实际情况以及河流的特点, 尽可能的保留河流的多样性和独特性, 切忌对成功案例的盲目效仿。

1.2 维护和保持河流自我恢复能力的原则。水利工程会在一定程度上 破坏河流环境, 但是由于河流具备一定的自我恢复能力, 其可以自发的进 行不同程度的恢复, 充分利用并维护河流的自我恢复能力, 不仅可以降低 水利工程对河流的负面影响, 而且自我恢复可以极大地避免了人为修复可 能引起的二次破坏, 总之, 这有利于实现河流生态环境的可持续发展。

1.3 以修复整个水域生态系统为目标的原则。河流生态系统不仅仅局 限在河流方面, 其与周围的城市、田地、乡村、森林等均有着密不可分的 联系, 这些元素共同构成了生态系统, 因此在建设水利工程的过程中, 应该 对生态环境中各个因素彼此之间的关系引起足够的重视。

\section{2 水利工程对生态环境的影响}

2. 1 河流生态环境的影响。水利工程基本上都是在天然河道上修建 的, 而这样使得河流长期演化成的生态环境受到了直接的破坏, 导致河 流局部形态的均一化和非连续化, 最终杀跌河流生态环境的多样性得到 了改变。水利工程建设对河流生态环境的具体影响表现在以下三个方面: 第一, 水利工程的建设使得天然河道的水质水温有所改变, 特别是对水库 的建设。水库由于其本身的一些特性加上外界太阳的辐射使得其具有特殊 的水温结构。并且由于在太阳辐射下增大了水面热量辐射值, 从而使得蓄 水后的坝前水温要高于天然河道水温, 严重影响了鱼类的繁殖; 第二, 影响 河流的水质。河流水速由于水利工程的建设而减小, 因此, 使得水、气界面

总之, 由于社会经济的不断发展, 针对水电等能源, 居民都提出了很高 的要求, 为了将人们的需求最大限度的满足, 对于水利水电建筑工程施工 技术的重视程度要极高。而水利水电项目在具体的应用中的效率直接受水 利水电建筑工程施工技术的影响, 因此, 为了将水利水电建筑的经济效益 和社会效益尽可能的提升, 就需要相关负责人将方案科学合理的制定, 并 且将技术管理力度进行加强, 以实际情况为基础, 将施工技术各个要点进 行掌握, 给水利水电建筑工程的质量提供保障。

\section{[参考文献]}

[1]舒超平.水利水电工程施工中的新技术应用和环境保护探讨 [J].江 西化工,2017,(06):175-176.

[2]杨向巍.水利水电工程建筑的施工技术及管理浅析 [J].水能经 济,2018,(06):79
交换的速率和污染物的迁移扩散能力受到了降低, 致使水质自净能力下降, 同时, 也会导致水质重金属污染严重; 第三, 影响气候和地质。水库的建设 会导致蒸发量将比水库建成前明显增大, 导致该区域的降水增多, 最终使 得原来的气候被改变。

2. 2水文环境影响。建设水利工程的时候, 基本上就是根据实际情况的 需求, 对原来天然河道结构与水文条件进行改变, 进而开展施工的过程。在 天然河道基础上进行水利工程的施工, 必然会影响水文环境。比如, 在河道 上进行堤坝建设, 就会在一定程度上, 减缓上游水流的流动速度, 降低水体 的自净能力; 在增加水库容量的时候, 必然会影响水温结构, 导致水体密 度、水中溶解氧、微生物、水生生物等出现变化, 对下游河道产生一定 的污染, 导致鱼类生存与繁衍的环境发生改变; 当水库中蓄水之后, 必然 会致使水库周围区域出现地下水水位上升的异常现象, 出现土壤环境改 变的问题。

\section{3 防范影响的有效对策}

3. 1 提高生态环境承载力。为了有效地减少水利工程对生态环境的影 响, 可以通过增加环境的承载力来实现更加密集的环境保护工作。在水利 工程过程中改变河道结构和水文条件时, 有必要确保河流本身的消耗量足 以确保环境的可持续发展。在社会经济增长不断发展的同时, 人们的生活 水平逐步提高, 在建设水利工程的过程中, 有必要加强农业补偿的实施。近 年来, 在水管理规划的背景下, 应在土地利用原则的实施中加强对农业用 地的支出, 并应根据环境的用水可能性选择合适的开发项目。例如, 在河谷 的狭窄区域, 河流上游的坡度较大, 经济发展水平较低, 可以建造水坝, 有 效减少中下游洪水的损失。

3. 2 强化不同施工阶段的生态环境保护工作。在实施水利工程建设的

[3]陆伟联.水利水电工程建筑的施工技术及管理浅析 [J].建材与装 饰,2018,538(29):293.

[4]汤达.浅析水利水电工程施工技术及其管理 [J].建筑 - 建材 - 装 饰,2018,(08):77.

[5]王畅.水利水电工程施工截流中可视仿真技术应用研究 [J]. 地下 水,2020,42(01):230-232.

[6]梁志宙.试析水利水电建筑工程施工技术及管理[ J]. 工程技术 (文摘 版),2017,(1):110.

作者简介：

叶镇瑜(1993--), 男, 广西北流人, 汉族, 本科, 助理工程师, 研究方 向: 水利水电建筑工程研究。 
时候, 一定要针对不同的施工阶段开展不同的生态环境保护工作。首先, 在合同签订阶段, 一定要对施工现场环境污染处理、污染物扩散处理的责 任进行规定, 提出有效的解决方案, 制定严格的污染指标, 并且保证相关工 作的全面落实。其次, 在施工管理阶段, 一定要建立环境保护监测机构, 对 施工过程中的水质、噪音、土壤、大气等方面进行测定, 之后对不同施工 阶段的测定结果进行比较, 明确生态环境的变化情况, 结合具体情况, 进行 相应的调整。最后, 在施工后期阶段, 在保护生态环境的时候, 主要就是对 破坏植被与景观的及时修复, 避免用地中出现耕地碾压的情况, 及时修复 耕地与植被, 全面实施绿化规划, 保证生态环境的可持续发展。

\section{4 生态水利工程的必要性}

水利工程生态化建设是人类社会发展对水利工程建设更高层次的需 求。在目前经济社会水利工程可以划分为 5 个层次: 饮水保障、防洪安全、 粮食供给、经济发展、生态环境。这 5 个层次最终都体现以人为本。水利 工程随着经济社会的快速发展, 已经进入到了更高的层次需求, 即生态环 境阶段。所以水利工程的建设必须突破以河论河、以水论水传统的束缚, 创造水和生态、水和文化、水和景观等的和谐。水利工程的建设, 在功能 定位上必须突出生态功能。

生态水利工程建设的必要性主要表现在既定目标的实现和实现可持 续发展两方面。在水利工程建设对生态环境影响中, 势必会发现会存在种 种问题, 解决了这些问题, 也就为既定目标的实现扫除了一些障碍。比如说 环境污染的问题, 植被破坏的问题, 水土流失的问题, 气候变化异常的问题, 水循环异常的问题, 湿土资源锐减的问题等, 都给人们敲响了警钟。只有解 决了这些问题, 人们经济发展的目标才有可能实现。在评价水利工程对生 态环境的影响过程中, 实质上就是在处理人类和自然的关系。只有将人类 和自然的关系处理清楚, 实现他们之前的和谐相处, 才能够实现可持续发 展, 这不仅表现在经济上的可持续发展, 而且社会各方面都能够得到可持 续发展。

\section{5 生态水利工程的建设途径}

5. 1 构建完善的生态水利工程制度。要想进一步加快生态水利工程的 建设进程, 就必须制定高效完善的制度, 也就是生态补偿制度和环境影响 评价制度。实际过程中, 为了对水库大坝等中的生产环境问题加以有效控 制, 必须执行完善的生态补偿制度。应构建完善的环境影响评价制度, 也就 是施工时要深入到现场分析研究拟建环境, 并据此编制相匹配的环境污染 治理方案, 它的内容基本上有水利工程建设前的环境调查, 及时了解周围
环境, 特别要检查此流域中水的问题与土壤的成分, 全面了解附近的环境。 并且应结合自身实际情况及相关因素, 准确的预测该工程施工中诸多的环 境影响因素, 提供相匹配的应对方案, 从而避免对周围环境造成大的影响。

5.2 处理好水污染问题。有效处理水污染问题已成为现阶段的关键。 可构建一个自然沉淀池, 使污水自然沉淀干净, 采用过滤、转化等诸多的 手段做好废水处理工作。施工作业时出现的大量污水应实施专业化处理, 方可开展下一道排放工作。

5.3 加强水利工程建设管理。水利工程建设管理是生态工程建设落实 执行的重要方式, 因此要加强水利工程建设管理。要做好合理规划。水利 工程的设计规划除了关注其经济效益外, 要将环境问题提上重要日程, 不 得以牺牲生态环境的代价换取经济的增长。工程设计、规划要兼顾经济效 益、社会效益及生态效益, 使得水利工程在为人们生产、生活提供更多便 利的同时, 还可以起到改善生态环境的作用。要优化施工方式以及机械设 备的使用, 对于具体的施工过程来说, 因为其不同的施工方式以及机械设 备的使用会产生不一样的生态环境污染效果, 因此, 针对这一方面的相关 选项进行严格的控制, 保障其各方面的威胁降到最低。

5. 4遵循生态规律。遵循生态规律, 是对生态水利工程最好的诠释。其 主要利用水自净、生态循环原理, 加之水利工程配套项目的开展, 在水资源 合理运用的同时, 做好生态环境保护工作, 例如: 生态养殖、生态农业相结 合项目, 其不仅可实现当地经济水平提升, 还可推进现代化农业的进步。

\section{6 结语}

总而言之, 在建设水利工程的时候, 必然会对生态环境产生一定的影 响。从水利工程对水文、土壤、生态平衡等方面的影响分析, 可以知道, 水利工程的建设, 对生态环境一定会产生影响, 是不可避免, 只可以进行 相应的防范与降低。而采用生态水利工程建设来对水资源进行开发利用, 不仅能够实现了对水资源的开发和利用, 而且还保护和尊重了自然生态 环境。

\section{[参考文献]}

[1]管世烽,夏振尧,陈毅,等.黔中水利枢纽工程生态环境评价体系研究 [J].安徽农业科学,2014,42(31):11180-11182.

[2]任改萍.水利工程对生态环境的影响以及生态水利工程[J].农民致 富之友,2019,(13): 125 .

[3]马荣华.农田水利工程对生态环境的影响及协调发展措施[J].中国 新技术新产品,2015,(20):166. 